\title{
Effects of extinction and US reinstatement of a blocking CS-US association
}

\author{
KAREN K. GUSTAVSON, JULIE A. HART, JEFFREY L. CALTON, \\ and TODD R. SCHACHTMAN \\ University of Missouri, Columbia, Missouri
}

\begin{abstract}
Rats were used in a conditioned taste-aversion procedure to examine the effects of extinction of a blocking CS-US association prior to the compound conditioning trials. Rats were initially given a pairing of a vinegar flavor with $\mathrm{LiCl}$. Some subjects then received three extinction trials with the vinegar flavor, and other subjects were given water. Subjects were then given compound stimulus conditioning trials in which a novel sucrose flavor, the target stimulus, was followed by vinegar and then a $\mathrm{LiCl}$ injection. The test on sucrose revealed a blocking effect for the subjects that did not receive the extinction trials, and blocking was attenuated for subjects that received extinction with vinegar. Also, prior to compound conditioning, some animals received a presentation of $\mathrm{LiCl}$ in the absence of any flavor-that is, US reinstatement. The results stemming from this treatment replicated a previous finding that US reinstatement treatment alters the ability of an extinguished CS to limit manifest learning about another association.
\end{abstract}

Extinction in classical conditioning is the decrement in the conditioned response (CR) that occurs when a conditioned stimulus (CS) that was previously paired with an unconditioned stimulus (US) is presented without the US. Extinction has long been acknowledged to be due to a masking of the CR acquired during the CS-US pairings. The view that extinction is due to masking suggests that the CS-US association is intact but not expressed. Demonstrations that an extinguished association is retained, but latent, typically use an unmasking treatment that reveals the association without allowing the potential for new learning. For example, one unmasking treatment of an extinguished association is imposing a period of time since the last nonreinforced CS presentation. The increase in CR with the next CS presentation is known as spontaneous recovery (Pavlov, 1927). Similarly, if the US is presented in the absence of the CS after extinction, then, at test, the CR to the CS increases-that is, unmasking occurs (e.g., Bouton \& Bolles, 1979; Rescorla \& Heth, 1975; Schachtman, Brown, \& Miller, 1985). This effect has been referred to as US reinstatement.

Although masking (e.g., extinction) causes low levels of CR, there has been little attention as to whether masking treatments may also prevent a CS's ability to influence manifest learning about another CS. Schachtman, Gustavson, Chelonis, and Bourne (in press) conducted flavor-aversion experiments showing that US reinstate-

Support for this research was provided by Research Council funds provided by the University of Missouri-Columbia. We thank M. Bourne, B. Butchart, J. Chelonis, and M. McEwen for their assistance with this project. We thank D. Wright for the use of his drinking tubes and S. Reilly for critically reading an early version of the paper. Address reprint requests to T. R. Schachtman, Department of Psychology, 210 McAlester Hall, University of Missouri, Columbia, MO 65211 . ment enhances the ability of an extinguished CS to limit manifest learning about an added CS. Rats were initially given a pairing of vinegar $(A)$ with $\mathrm{LiCl}$-induced illness $(+)$, followed by three extinction trials in which $A$ was presented without $\mathrm{LiCl}(\mathrm{A}-)$. Subjects were then given compound stimulus conditioning in which a sucrose flavor $(X)$, the target CS, was followed by vinegar and then $\mathrm{LiCl}$ (i.e., $X A+$ trials). Prior to compound conditioning, some animals received a presentation of $\mathrm{LiCl}$ in the absence of flavor (i.e., US reinstatement). It was found that reinstatement enhanced the potential of the extinguished CS $(A)$ to limit learning about the added stimulus $(X)$. In other words, following US reinstatement, an extinguished CS was able to block new manifest learning relative to either a condition that did not receive reinstatement or blocking control conditions.

In the experiments by Schachtman et al. (1992), it was assumed that $A$ would block conditioning to $X$ on the compound conditioning trials if $A$ had not been extinguished. Indeed, this is the well-documented basic blocking effect (e.g., Kamin, 1969). It was also assumed that the $A-$ extinction trials reduced the ability of $A$ to block $X$. The result would be expected on the basis of most current theories of classical conditioning (e.g., Rescorla \& Wagner, 1972). However, poor blocking by an extinguished CS is not so obvious when it is considered that extinction results in the masking of associative strength rather than an elimination of associative strength. Schachtman et al. found that US reinstatement enhanced the ability of an extinguished, pretrained stimulus to limit learning about an added stimulus. However, because the experiments were interested in the effects of US reinstatement, the experiments did not compare groups that did or did not receive extinction of the pretrained $\mathrm{CS}$ on its blocking potential. In the present experiment, we sought to com- 
pare these conditions as well as replicate the reinstatement effect obtained in the previous report.

The experiment used a procedure similar to that used by Schachtman et al. (1992). Three groups received flavor conditioning with vinegar. Two of these groups (Groups $R$ and $R C$ ) then received extinction trials with vinegar. Group NE did not receive extinction. After extinction, Group R received US reinstatement. Additional control subjects were trained with an irrelevant flavor during these initial phases of the experiment. All subjects then received serial, compound conditioning with vinegar and the target solution, sucrose. It was expected that blocking would occur for Group NE when learning about sucrose was compared with the subjects that had been trained with an irrelevant CS during the initial phases of training (i.e., a conventional blocking effect). Moreover, it was expected that Group RC would yield poor blocking due to the extinction of vinegar prior to compound conditioning. Finally, it was expected that blocking would be found for Group R, replicating the effects obtained by Schachtman et al. (1992).

\section{METHOD}

\section{Subjects}

Thirty-six male and 36 female, naive, Sprague-Dawley-derived rats served as subjects. At the start of the study, the body weights of the female rats were between 190 and $293 \mathrm{~g}$ and those of the male rats were between 236 and $410 \mathrm{~g}$. Each rat was individually housed in hanging, stainless steel wire-mesh cages with ad-lib access to lab chow. The subjects were gradually water deprived prior to the start of the experiment, culminating in 10-min water access each day in the home cage after each day's session.

\section{Apparatus}

All treatments, except the reinstatement treatment, occurred in the home cage. A modified, inverted 50 -ml syringe with a metal licktube attached served as the drinking tube. $\mathrm{LiCl}(2 \%[\mathrm{w} / \mathrm{v}]$ at $1 \%$ body weight-i.e., $200 \mathrm{mg} / \mathrm{kg}$ ) was administered by intraperitoneal injection using a $25-\mathrm{ga}, 1.59-\mathrm{cm}$ hypodermic needle. The $\mathrm{LiCl}$ reinstatement treatment occurred in a different context from the home cage. See Schachtman et al. (in press) for details.

\section{Procedure}

Half of the animals were assigned to the condition receiving coffee in the initial phase of the study and the remaining animals were assigned to conditions receiving vinegar, counterbalancing as much as possible for body weight and sex.

On Day 1, the subjects to become Groups R (reinstatement), NE (no extinction), and RC (reinstatement control) received 15-min access to a 3\% Heinz apple cider vinegar (Vin) solution; Groups C-R, C-RC, and

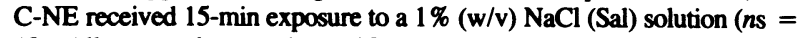
12). All groups then received $\mathrm{LiCl}$. All flavored solutions were recorded by weighing the drinking tubes before and after treatment. If an animal did not drink $2 \mathrm{ml}$ or more of a solution during the initial exposure to the solution when it was the first solution of the session, the animal was eliminated from the experiment due to insufficient CS exposure.

The subjects remained in the home cage on Day 2 (as well as on Days 7 and 9) to ensure recovery from illness. Days 3, 4, and 5 were extinction trials for all groups, except Groups NE and C-NE. During extinction, the subjects received a $15-\mathrm{min}$ access to the flavor that had been experienced during conditioning, and Groups NE and C-NE received a 15-min exposure to water. The subjects that received extinction trials were assigned to Group R or Group RC at this time (if they had been pretrained on Vin) or Group C-R or Group C-RC (if they had been pretrained on Sal) and were counterbalanced for sex, body weight, and consumption of the flavor on the final extinction trial.
On Day 6, Groups $R$ and $C-R$ received a reinstatement treatment. Each animal was placed in a reinstatement chamber for $10 \mathrm{~min}$ prior to the administration of $\mathrm{LiCl}$ identical to that of Day 1 . Reinstatement was given in a context different from the context where flavor conditioning and testing occurred. This context change attenuated the potential for associations between the reinstatement context and the US to contribute to the effects of reinstatement, such as through the summation of excitatory contextual cues with the test stimulus at testing (see Bouton \& Bolles, 1979). After the $\mathrm{LiCl}$ injection, the animals remained in the reinstatement chamber for $1 \mathrm{~h}$ and were then returned to the home cage. The subjects in Groups RC, NE, C-NE, and C-RC did not receive the reinstatement treatment, and these subjects remained in the home cage on Day 6. On Day 7, the subjects received no treatment.

Day 8 consisted of serial compound CS conditioning trials for all animals. Each animal received a 7.5-min exposure to a $12 \%(\mathrm{w} / \mathrm{v}) \mathrm{su}-$ crose (Suc) solution, which was followed immediately by 7.5 -min access to $\mathrm{Vin}$. After exposure to $\mathrm{Vin}$, all subjects received a $\mathrm{LiCl}$ injection similar to that of Day 1. On Day 9, the animals received no experimental treatments. All animals were given 15-min, nonreinforced test exposures to Suc on Days 10 and 11 .

In summary, Groups R, RC, and NE were initially conditioned with Vin. Group NE received no extinction with Vin and was comparable to a conventional blocking condition. Groups $\mathrm{R}$ and $\mathrm{RC}$ received extinction of Vin; the former group also received reinstatement. Groups C-NE, C-RC, and C-R served as blocking control conditions initially trained on Sal but were otherwise treated identically to Groups NE, RC, and $R$, respectively.

\section{RESULTS AND DISCUSSION}

Five subjects were lost from the study (one from each of Groups NE, C-RC, and C-R, and two from Group C-NE) due to illness or failure to drink a solution when it was the subject's initial solution of the day and prior to being paired with $\mathrm{LiCl}$. The animals trained on Day 1 with a flavor that was not present on the compound CS training phase (i.e., subjects in Groups C-R, C-RC, and C-NE) did not differ from each other in their test performance; therefore, the data from these subjects were combined to form Group $C$. The results of the analysis on these conditions revealed no effect of group $(p>.30)$, although there was an effect of day $[F(1,29)=93.09$, $p<.0001]$ but no interaction $(p>.20)$.

Mean consumption on the Day 1 conditioning trial was $11.0 \mathrm{ml}( \pm 1.0), 10.6 \mathrm{ml}( \pm 0.9), 10.8 \mathrm{ml}( \pm 0.6)$, and $17.9 \mathrm{ml}( \pm 0.6)$ for Groups NE, R, RC, and C, respectively. There was a significant difference among groups in the amount of solution consumed on this trial $[F(3,63)=$ $16.63, p<.0001]$. This effect occurred because the amount of Sal consumed by Group $C$ was more than the amount of Vin consumed by the other groups ( $p s<.01)$. There were no differences in consumption among groups exposed to Vin on Day 1 ( $p s>.10)$.

Mean consumption on the extinction trials was $2.7 \mathrm{ml}$ ( \pm 0.2$), 7.4 \mathrm{ml}( \pm 0.5)$, and $11.5 \mathrm{ml}( \pm 0.6)$ for Group $\mathrm{R}$, $3.0 \mathrm{ml}( \pm 0.3), 7.8 \mathrm{ml}( \pm 0.6)$, and $11.6 \mathrm{ml}( \pm 0.8)$ for Group RC, and $5.3 \mathrm{ml}( \pm 0.6), 12.6 \mathrm{ml}( \pm 1.1)$, and $15.1 \mathrm{ml}( \pm 1.2)$ for Group C. A group $\times$ day analysis of variance (ANOVA) conducted on consumption on the conditioning trial and initial extinction trial obtained significant effects of group $[F(2,43)=36.21, p<.0001]$ and day $[F(1,43)=324.52, p<.0001]$, and a group $\times$ day interaction $[F(2,43)=8.76, p<.001]$. The group effects occurred because the amount of Sal consumed by 
Group C, particularly on Day 1, was more than the amount of Vin consumed by all other groups $(p s<.01)$, and, hence, the former group yielded a greater relative decrease in consumption as a result of conditioning. The groups that consumed Vin on these days did not differ from each other ( $p s>.10)$.

A group $\times$ day ANOVA examining the three extinction days revealed significant main effects of group $[F(2,43)=$ $9.82, p<.0005]$ and day $(p<.0001)$, but no interaction $(F<1)$. Again, this main effect of group occurred because the amount of Sal consumed by Group $\mathrm{C}$ was more than the amount of Vin consumed by all other groups ( $p s<.01$ ). The groups that received Vin on these trials did not differ from each other ( $p s>.10$ ).

Groups NE, R, RC, and C consumed, respectively, $13.8 \mathrm{ml}( \pm 1.2), 15.1 \mathrm{ml}( \pm 1.2), 12.0 \mathrm{ml}( \pm 0.9)$, and $12.3 \mathrm{ml}( \pm 0.7)$ of Suc on the compound conditioning trial. All groups drank comparable amounts of Suc on this trial ( $p$ s > .10). Groups NE, R, RC, and C consumed, respectively, $0.9 \mathrm{ml}( \pm 0.2), 6.5 \mathrm{ml}( \pm 0.8), 4.9 \mathrm{ml}$ $( \pm 0.5)$, and $4.3 \mathrm{ml}( \pm 0.3)$ of Vin on the compound conditioning trial. Significant group differences occurred for these scores $[F(3,63)=20.36, p<.0001]$. These differences emerged because Group NE consumed less Vin than did each of Groups R, RC, and C ( $p s<.01)$-an expected effect given that Group NE received no extinction trials with Vin. Group $C$ consumed less Vin than Group $\mathbf{R}$ on the compound conditioning trial $(p<.01)$. Group $\mathbf{R}$ consumed significantly more Vin than did Group RC $(p<$ $.05)$. Differential consumption of Vin on the compound trial produced a potential confound. However, the substantially lower consumption of Vin by Group NE than by Groups R and RC should have attenuated learning about Vin and allowed more learning about Suc than would otherwise occur, thereby working against an effect of attenuating learning about Suc for this condition. The difference between Group R and Group RC poses a confound; however, experiments reported by Schachtman et al. (in press) revealed that test performance differences do not depend on this consumption difference.

The test data are shown in Figure 1. As mentioned above, there was no difference in consumption for subgroups of Group $C$ on the test trials (i.e., Groups C-R, C-RC, and C-NE), and the data for these subgroups were combined to form Group C. Statistical analysis comparing Groups $\mathrm{C}-\mathrm{R}$ and $\mathrm{C}-\mathrm{RC}$ produced no main effect of group $(F<1)$ and no group $\times$ day interaction $(p>.10)$.

An ANOVA (group $\times$ day) conducted on consumption of Suc on the test trials yielded group-mean differences $[F(3,63)=2.73, p=.05]$ and a main effect of day $(p<$ $.0001)$; the group $\times$ day interaction approached statistical significance $[F(3,63)=2.62, p=.059]$. The level of significance of the interaction encouraged the examination of specific group comparisons. A simple main effects analysis obtained no group differences on Test Day 1 $(p>.10)$. Group differences were present on Test Day 2, as revealed by a simple main effects analysis $[F(3,90)=$ $3.32, p=.03$ ]. Group NE consumed more Suc during the test than did Group RC, as indicated by a group $\times$

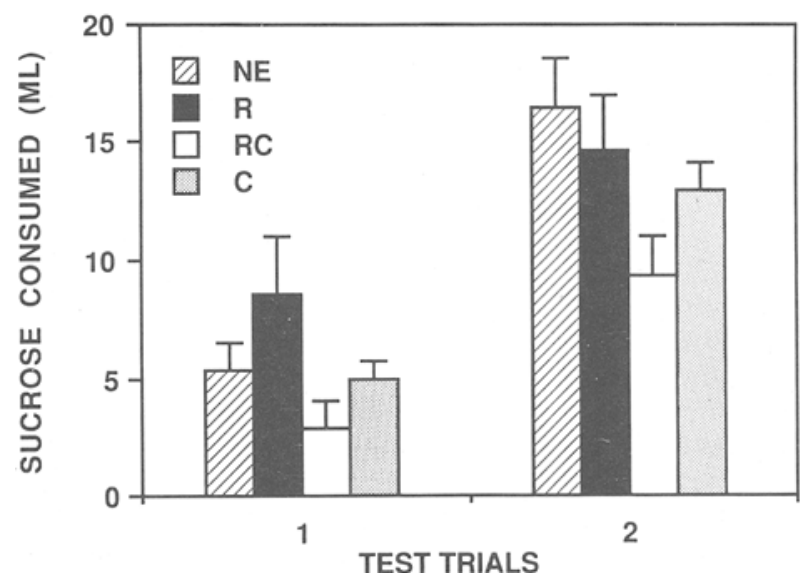

Figure 1. Mean intake of sucrose as a function of treatment on the test trials in Experiment 1. Error bars indicate SEMs.

day ANOVA that yielded main effects of group $[F(1,21)$ $=6.26, p<.03]$ and day $(p<.0001)$ and a group $\times$ day interaction $[F(1,21)=4.72, p<.05]$. This indicated that extinction of Vin for Group RC produced a greater aversion to Suc compared to a group that did not receive extinction of Vin. However, the rate of extinction of Suc for Group NE was only marginally more rapid than that for Group C, as indicated by the results of an ANOVA that produced a group $\times$ day interaction $[F(1,41)=2.94$, $.05<p<.10]$. Hence, the poor learning about Suc for Group NE, relative to Group C, was not large. Group R yielded significantly greater consumption across the test trials than did Group RC $[F(1,22)=4.93, p<.05]$, indicating that blocking of learning about Suc can be induced if US reinstatement of the extinguished association occurs prior to compound conditioning.

Consistent with the effects reported by Schachtman et al. (1992), reinstatement of an extinguished stimulus enhanced its potential to restrict manifest learning about another stimulus. However, the present experiment also showed that extinction of the pretrained stimulus (Vin) promoted greater learning about Suc than did a condition in which the pretrained stimulus was not given extinction treatment. Extinction of Vin reduced the blocking that occurred for Group NE. Reinstatement following extinction returned the subjects to the state for which Vin again limited learning about Suc. For the subjects for which Vin and Suc were both novel at the time of compound conditioning (Group C), Suc became associated with illness. For Group RC, learning about Suc was enhanced somewhat, relative to that for Group $C$, because Vin received extinction prior to the compound conditioning trials for the former group. The difference between Groups NE and RC supports this claim. Previous studies have also shown that nonreinforced exposure of a CS (e.g., latent inhibition) can make it relatively poor at attenuating learning about another element of a compound (Navarro, Hallam, Matzel, \& Miller, 1989; Revusky, Parker, \& Coombes, 1977). 
The mechanism by which reinstatement influences manifest learning about Suc in the present experiment requires consideration. Habituation to the US may have exerted some influence in the reinstatement effect, but it was unlikely the major contributing factor. If habituation were the sole factor underlying these reinstatement effects, then one would expect that reinstatement given to subjects originally trained on Day 1 with a flavor that was not present on the compound conditioning trials (i.e., subjects in Group C that were given reinstatement) should have yielded as large a retardation of learning as groups given original training with the pretrained stimulus.

It is unlikely that the attenuation of learning about Suc for Group R was produced by context-US associations formed during the reinstatement treatment influencing test performance. This reinstatement treatment was intentionally given in a radically dissimilar context from where conditioning and testing occurred so that generalization between the reinstatement context and the flavor conditioning/test context was minimized.

It was suggested by Schachtman et al. (1985) that extinction reduces the subject's ability to retrieve the previously acquired CS-US association. Moreover, US reinstatement improves retrieval of this association (see also Miller, Kasprow, \& Schachtman, 1986). The present results show that retrieval of the association between the blocking stimulus and the US at the time of compound conditioning appears to exert a large influence on blocking.

Balaz, Gutsin, Cacheiro, and Miller (1982) and Schachtman, Gee, Kasprow, and Miller (1983) have shown that postconditioning procedures called reminder treatments can reverse blocking performance deficits. Such treatments presumably improve performance at test by enhancing the retrievability of the association between the target CS and the US (i.e., the blocked CS-US association), and this improvement in retrieval enhances the $C R$ at the time of testing. Hence, blocking has been suggested to be due to a retrieval deficit at the time of testing the target CS, rather than an acquisition deficit.

If a retrieval interpretation of the present reinstatement effects on blocking is accepted, then the present results suggest that blocking is influenced by the retrievability of the blocking CS-US association at the time of compound trials. Thus, when viewed in concert with the finding that blocking may be a retrieval failure due to poor retrievability of the association between the blocked association and the US (Balaz et al., 1982), then the retrievability of one CS-US association (the blocking association) appears to determine the retrievability of another CS-US association (the blocked association). It is worth noting that this process of retrieval competition is similar to the concepts of output interference, retrieval blocking, and cue overload in human memory (e.g., Karchmer \& Winograd, 1971; Stern, 1985, pp. 113-118; Watkins $\&$ Watkins, 1976). These processes occur when retrieval of one (typically stronger) association inhibits the retrieval of other (usually related) associations.

The possibility of competition between CSs for retrievability during compound conditioning stands in sharp con- trast to US-effectiveness (Rescorla \& Wagner, 1972) and CS-effectiveness (Mackintosh, 1975; Pearce \& Hall, 1980) models of classical conditioning that focus on competition for the acquisition of associative strength. The present results can be viewed as consistent with the claim by Balaz et al. (1982) that the processes that limit CS effectiveness and/or US effectiveness may be factors that influence efficient retrieval at the time of test.

\section{REFERENCES}

Balaz, M. A., Gutsin, P., Cacheiro, H., \& Miller, R. R. (1982). Blocking as a retrieval failure: Reactivation of associations to a blocked stimulus. Quarterly Journal of Experimental Psychology, 34B, 99-113.

Bouton, M. E., \& Bolles, R. C. (1979). Role of conditioned contextual stimuli in reinstatement of extinguished fear. Journal of Experimental Psychology: Animal Behavior Processes, 5, 363-378.

KAmin, L. J. (1969). Predictability, surprise, attention, and conditioning. In B. A. Campbell \& R. M. Church (Eds.), Punishment and aversive behavior (pp. 279-296). New York: Appleton-Century-Crofts.

KARCHMER, M. A., WinOGRAD, E. (1971). Effects of studying a subset of familiar items on recall of the remaining items: The John Brown effect. Psychonomic Science, 25, 224-225.

MACKInTosh, N. J. (1975). A theory of attention: Variations in the associability of stimuli with reinforcement. Psychological Review, 82, 276-298.

Miller, R. R., Kasprow, W. J., \& Schachtman, T. R. (1986). Retrieval variability: Sources and consequences. American Journal of Psychology, 99, 145-218.

Navarro, J. I., Hallam, S. C., Matzel, L. D., \& Miller, R. R. (1989). Superconditioning and overshadowing. Learning \& Motivation, 20, 130-152.

Pavlov, I. P. (1927). Conditioned reflexes. Oxford: Oxford University Press.

Pearce, J. M., \& Hall, G. (1980). A model for Pavlovian learning: Variations in the effectiveness for conditioned but not of unconditioned stimuli. Psychological Review, 87, 532-552.

Rescorla, R. A., \& HeTH, C. D. (1975). Reinstatement of fear to an extinguished conditioned stimulus. Journal of Experimental Psychology: Animal Behavior Processes, 1, 88-96.

Rescorla, R. A., \& Wagner, A. R. (1972). A theory of Pavlovian conditioning: Variations in the effectiveness of reinforcement and nonreinforcement. In A. H. Black \& W. F. Prokasy (Eds.), Classical conditioning: II. Current research and theory. New York: AppletonCentury-Crofts.

Revusky, R., PArker, L. A., \& Coombes, S. (1977). Flavor aversion learning: Extinction of the aversion to an interfering flavor after conditioning does not affect the aversion to the reference flavor. Behavioral Biology, 19, 503-508.

Schachtman, T. R., Brown, A. M., \& Miller, R. R. (1985). Reinstatement-induced recovery of a taste- $\mathrm{LiCl}$ association following extinction. Animal Learning \& Behavior, 13, 223-227.

Schachtman, T. R., Gee, J.-L., Kasprow, W. J., \& Miller, R. R. (1983). Reminder-induced recovery from blocking as a function of the number of compound trials. Learning \& Motivation, 14, 154-164.

Schachtman, T. R., Gustavson, K. K., Chelonis, J. J., \& Bourne, M. J. (in press). Effects of US reinstatement on the potential of an extinguished CS to attenuate manifest learning about another CS. Learning \& Motivation.

STERN, M. J. (1985). The structures and strategies of human memory. Homewood, IL: Dorsey.

Watkins, M. J., Watkins, O. C. (1976). Cue-overload theory and the method of interpolated attributes. Bulletin of the Psychonomic Society, 7, 289-291.

(Manuscript received February 3, 1992.) 